\title{
Distribution Failure Interruption Evaluation Based on the Cloud Model
}

\author{
Lina Jiao \\ Electrical Engineering Department \\ Shandong Polytechnic \\ Jinan, China \\ E-mail: Jiao_lina @126.com
}

\begin{abstract}
To analyze and evaluate the distribution network failure interruption, this paper establishes the comprehensive evaluation index power distribution network failure interruption. By using the normal cloud model, this paper also realizes the risk evaluation of power distribution network fault. First, fault risk sources are classified and divided into internal risk sources and external risk sources. Based on this, key risk sources are identified. Then, risk indices of the distribution network fault are analyzed, and the comprehensive evaluation index system is established. By using the characteristics of the normal cloud model, this paper proposes a risk evaluation method based on the normal cloud model for the distribution network. This paper takes a city in the southeast of China as a sample. This method is verified, and some advices for distribution network operation maintenance are proposed. Practice proved that the normal cloud model failure risk evaluation overcomes uncertainty, random and fuzzy problems of the indicators value. This method can carry on the reasonable evaluation of distribution network power failure interruption.
\end{abstract}

Keywords-Failure Interruption; Power Distribution Fault; Risk Evalution; Cloud Model; Power Distribution

\section{INTRODUCTION}

Electric power distribution is the last stage in the delivery of electricity system, and carries electricity from the transmission system to individual consumers. It is important part of improving power supply quality. The statistical data from the State Electricity Regulatory Commission of China (SERC) and the Office of Gas and Electricity Markets (Ofgem) show that the failure interruption caused by distribution network is over $80 \%$ of the power failure interruption [1-3].Therefore, it is an important role for improving power quality and planning distribution network to master the operation state and the latent faults of distribution network as early as possible.

The main cause of failure interruption (FI) for the distribution network is climatic, environmental, external damage, internal fault, erroneous operation, and so on. Some method is used for risk evaluation, such as transient time varying equipment outage model [4,5], the generalized regression neural network [6,7]. These models and algorithms fully consider the fuzziness of risk indices and failed to fully consider the randomness. However, the occurrence of fault often has randomness, which reduces the accuracy of the state evaluation. The cloud theory is used in this paper. The fault has a characteristic of normal distribution. So, the normal cloud model is used in this paper for analysis fault factors.

\section{FAILURE INTERRUPTION SOURCE}

\section{A. Risk source analysis}

According to China Guide on security and stability for power system [8], the failure can be divided to three types, equipment failure, feeder failure, and system failure. And the fault risk source object of the distribution network can be divided into equipment level, feeder level, and system level. The equipment level risk source objects are single power equipments, such as overhead lines, cables, polemounted switches, pole-mounted transformers, secondary substation equipments, and so on. The feeder level objects are the whole feeder made up of distribution branches, distribution substations, switches, and loads. The system level monitoring objects consists of feeder distribution system within the whole of concerned areas.

There are many failure risk sources in the distribution network, such as the failure of the equipment, the uncertainty of the load, and the wrong operation. The risk sources can be divided into internal risk and external risk. The internal risk refers to the power distribution network itself. The external risk refers to the risk caused by the management and operation mechanism. The internal risk and external risk is shown in Table I.

\section{B. Key Risk Source Identification.}

Based on the basic risk factors listed in Table I, researchers use expert investigation method and the matrix analysis method to identify major risk factors for failure interruption. Major risk factors are also named as the key risk sources. During design the risk questionnaire, the external grid environment and distribution system are the priority problem, and the operation, load control, management, people ware problem is omitted. After discussion and selection by experts, adjustment of the internal and external risk factors, the key risk sources of distribution network are proposed as shown in Table II. 
TABLE I. EXTERNAL FAILURE RISK

\begin{tabular}{|c|c|c|}
\hline \multicolumn{2}{|c|}{ Risk Type } & Risk Factors \\
\hline \multirow{8}{*}{$\begin{array}{l}\text { External } \\
\text { failure }\end{array}$} & \multirow{5}{*}{$\begin{array}{l}\text { Management } \\
\text { mechanism }\end{array}$} & Management mechanism changing \\
\hline & & Cost saving \\
\hline & & Power flow changing \\
\hline & & Complexity of grid operation \\
\hline & & Change of safety responsibility system \\
\hline & \multirow{3}{*}{ Environment } & Natural disasters, environmental pollution \\
\hline & & $\begin{array}{l}\text { Power facilities are stolen, offline illegal } \\
\text { operation breakdowns }\end{array}$ \\
\hline & & Laws and regulations system, operability \\
\hline \multirow{10}{*}{$\begin{array}{l}\text { Internal } \\
\text { failure }\end{array}$} & \multirow{3}{*}{$\begin{array}{l}\text { Distribution } \\
\text { network } \\
\text { infrastructure }\end{array}$} & $\begin{array}{l}\text { Grid network spare capacity is } \\
\text { insufficient }\end{array}$ \\
\hline & & Outdated equipment \\
\hline & & $\begin{array}{l}\text { Low level of the equipment maintenance } \\
\text { and repair }\end{array}$ \\
\hline & \multirow{2}{*}{ Operation } & Complex operation ticket \\
\hline & & The dispatcher lack of experience \\
\hline & Load control & Load forecast is not accurate \\
\hline & \multirow{3}{*}{ Management } & organization criterion \\
\hline & & Organizational communication \\
\hline & & Tissue function failure \\
\hline & People ware & $\begin{array}{l}\text { Part of the field operation personnel } \\
\text { qualityl lack of personnel training }\end{array}$ \\
\hline
\end{tabular}

TABLE II. EXTERNAL FAILURE RISK

\begin{tabular}{|l|l|}
\hline \multicolumn{1}{|c|}{ Risk Type } & \multicolumn{1}{|c|}{ Risk Factors } \\
\hline $\begin{array}{l}\text { Distribution } \\
\text { equipment }\end{array}$ & $\begin{array}{l}\text { Life of equipment; Equipment defect; Potential } \\
\text { equipment;Overload; Earthing mode }\end{array}$ \\
\hline Distribution grid & The system transport capacity. \\
\hline Customer & Customer failure \\
\hline $\begin{array}{l}\text { Natural and } \\
\text { climatic }\end{array}$ & Lightning;Heavy rain; Bad weather \\
\hline $\begin{array}{l}\text { Construction } \\
\text { destruction }\end{array}$ & Construction destruction \\
\hline Seasonal & Seasonal factor \\
\hline
\end{tabular}

\section{RISK EVALUATION INDICES OF FAILURE} INTERRUPTION

\section{A. Reliability on Services Indices}

The main function of the power system is to provide an adequate electrical supply to its customers. The cost of a major power outage confined to one state can be on the order of tens or hundred of millions of dollars. Therefore, maintaining a reliable power supply is a very important issue for power systems. Reliability indices are measures of power system quality. In China, the most widely used reliability indices are: reliability on service (RS), average interruption hours $(\mathrm{AIH})$, average failure interruption customer (AIC). These indices are define in reliability evaluation code for customer service in power supply system [9].
AFIH is the average failure interruption hours during the period (one year) of the statistics.

$$
\text { AFIH }=\frac{\sum F I \text { Durations Hours }}{\text { Total Failure Number }}
$$

AFIC is the average failure interruption customers number during the period (one year) of the statistics.

$$
A F I C=\frac{\sum \text { FI Customers }}{\text { Total Failure Number }}
$$

AIHC is the average power interruption hours during the period (one year) of the statistics.

$$
\text { AIHC }=\frac{\sum \text { Interruption Hours }}{\text { Total Customer Number }}
$$

RS is reliability on service, and is a ratio of the effective power supply hours to customer and the number of hours during the statistics.

$$
R S=1-\frac{A I H C}{\text { Total Number Hours of Statistical }}
$$

AFEN is the average energy not supplied due to failure interruption during the statistics.

$$
A F E N=\frac{\sum \text { Average Energy not Supplied FI }}{\text { Total Number of FI }}
$$

\section{B. Customer outage loss}

The loss of outage refers to the economic loss caused by the interruption of power supply to the customers. The power loss of the customers can be calculated by indirect estimation. The method is to put electricity as a factor of production, and then estimate the economic output per unit of electricity in the same circumstances as the other factors unchanged.

$$
O C=\text { Energy not Supplied } \times \frac{G D P}{\text { Energy Cost }}
$$

\section{Comprehensive evaluation index.}

Based on the above indices, the comprehensive evaluation index is proposed, $\mathrm{U}=\{\mathrm{U} 1, \mathrm{U} 2, \mathrm{U} 3, \mathrm{U} 4, \mathrm{U} 5$, $\mathrm{U} 6\}=\{A F I H . A F I C, A I H C, R S, A F E N, O C\}$.

\section{Risk Evaluation Method BASEd on Cloud MODEL}

\section{A. Cloud Model Overview}

In 1995, the concept of the cloud model was put forward based on the theory of probability and fuzzy mathematics by Chinese scholar Li Deyi academicians [10-11]. The transition model between qualitative concepts and quantitative representations is formed by the specific 
structure of the cloud model, and the inherent correlation between the randomness and fuzziness is revealed. The cloud model has the integrity and the aggregation. As the cloud, it has the obvious shape seeing far and has no clear edge from near. Most of the random phenomena are subject to the normal distribution, and the normal cloud is more universal [12]. Cloud is composed of many cloud droplets. The overall shape of the cloud reflects the important characteristics of qualitative. And the cloud is a quantitative description of the qualitative.

The numerical characteristics of cloud model are represented by $E x, E n$ and $H e$, rember as $\mathrm{Sc}(E x, H e, E n)$,

Where,

$E x$ is expectation of the cloud model, center of gravity position of the cloud;

$E n$ is the entropy, which reflects the uncertainty of the qualitative concept;

$H e$ is the super entropy, and is the measure of the entropy of the entropy, which reflects the degree of the cloud.

\section{B. Distibution Risk Evaluation}

Distribution network fault risk evaluation is a comprehensive analysis of the consequences of failure probability and failure, and the assessment content mainly includes two aspects of failure probability and severity. Research on distribution network failure interruption risk found that lead to failure of the index itself has a certain ambiguity and uncertainty, fault and a random, this can be a positive normal cloud model, introduced to the distribution network power failure risk evaluation.

In the cloud model, the virtual cloud is a kind of application, and can be considered as a kind of virtual cloud in the risk evaluation of distribution network failure interruption.

\section{Risk Evaluation method}

The concrete steps of the risk evaluation of power distribution network failure interruption based on cloud model are as follows:

(1) Establish failure interruption evaluation indices set for distribution network.

(2) Build the evaluation set cloud model.

(3) Establish the weight of the assessment index.

(4) Obtain the numerical characteristics of the index values and the establishment of the basic cloud model.

(5) Create the comprehensive cloud and combine with the weight allocation.

(6) AnalyZE the failure risk of the fault.

\section{Risk Evaluation OF DistribUtion IN A CiTY}

According to the risk evaluation method discussed above, the risk evaluation of the fault of the power distribution network in a city of South China in 2011 is carried out. The risk evaluation results as below.

(1) Establish indicator sets.

Using the comprehensive index as discussed above.

$\mathrm{U}=\{\mathrm{U} 1, \mathrm{U} 2, \mathrm{U} 3, \mathrm{U} 4, \mathrm{U} 5, \mathrm{U} 6\}=\{A F I H . A F I C, A I H C$, $R S, A F E N, O C\}$.

(2) Build the basis of the cloud model.

Based on the index set, evaluation set is established, = $E S=$ (low-low, low, normal, high, high-high), the risk degree of interval respectively, low-lowe [0,0.3), low
$[0.3,0.45)$, normal $[0.45,0.55)$, high $[0.55,0.7)$, high-high $[0.7,1]$. For each comment, the cloud model is as follows:

$\operatorname{SCv} 1(0,0.1,0.005)$,

$\operatorname{SCv} 2(0.375,0.025,0.002)$

$\mathrm{SCv} 3(0.5,0.025,0.002)$,

$\mathrm{SCv} 4(0.625,0.025,0.002)$

$\mathrm{SCv} 5(1,0.1,0.005)$.

(3) Determine index weight

First calculate the index weight $W i$, and then normalize $W i$ get weight $W i^{*}$, and $\mathrm{i}$ is the index of importance. The result is shown in Table III.

(4) Calculate the numerical characteristics of the index.

Calculate the number of features, and establish a basic cloud model.

(5) Calculate comprehensive evaluation objects cloud, the result is Table V.

(6) Analysis of computing result.

According to the calculation result of Table IV, into the characteristics of positive cloud generator is generated.

TABLE III. INDICATOR WEIGHT OF RISK EVALUSION

\begin{tabular}{|l|c|l|l|}
\hline \multicolumn{1}{|c|}{ Index } & Order & Wi & $\mathbf{W i}^{*}$ \\
\hline AFIH & 1 & 1 & 0.2355 \\
\hline AFIC & 1 & 1 & 0.2355 \\
\hline AIHC & 2 & 0.747 & 0.1758 \\
\hline RS & 3 & 0.650 & 0.1531 \\
\hline$A F E N$ & 4 & 0.500 & 0.1177 \\
\hline$O C$ & 5 & 0.350 & 0.0824 \\
\hline
\end{tabular}

TABLE IV. INDICATOR WEIGHT OF RISK EVALUSION

\begin{tabular}{|l|l|l|l|}
\hline Equipment Object & Ex & En & He \\
\hline Overhead line & 0.644 & 0.267 & 0.003 \\
\hline Pole Transformer & 0.467 & 0.108 & 0.005 \\
\hline Pole equipment & 0.441 & 0.157 & 0.002 \\
\hline Cable line & 0.448 & 0.237 & 0.003 \\
\hline Secondary substation & 0.497 & 0.500 & 0.0818 \\
\hline
\end{tabular}


TABLE V. INDICATOR WEIGHT OF RISK EVALUSION

\begin{tabular}{|c|c|c|c|c|c|c|c|}
\hline \multicolumn{2}{|c|}{ Index } & $U 1$ & $U 2$ & $\boldsymbol{U 3}$ & U4 & U5 & U6 \\
\hline \multirow{3}{*}{$\begin{array}{l}\text { Overhe } \\
\text { ad line }\end{array}$} & $E x$ & 0.938 & 0.329 & 0.906 & 0.180 & 0.488 & 0.707 \\
\hline & $E n$ & 0.062 & 0.334 & 0.621 & 0.045 & 0.312 & 0.258 \\
\hline & $\mathrm{He}$ & 0.004 & 0.004 & 0.001 & 0.002 & 0.005 & 0.004 \\
\hline \multirow{3}{*}{$\begin{array}{c}\text { Pole } \\
\text { Transfo } \\
\text { rmer }\end{array}$} & $E x$ & 0.151 & 0.016 & 0.378 & 0.620 & 0.488 & 0.707 \\
\hline & $E n$ & 0.057 & 0.022 & 0.096 & 0.095 & 0.312 & 0.258 \\
\hline & $\mathrm{He}$ & 0.003 & 0.005 & 0.003 & 0.003 & 0.005 & 0.004 \\
\hline \multirow{3}{*}{$\begin{array}{c}\text { Pole } \\
\text { equipm } \\
\text { ent }\end{array}$} & $E x$ & 0.350 & 0.291 & 0.729 & 0.360 & 0.488 & 0.707 \\
\hline & $E n$ & 0.024 & 0.262 & 0.078 & 0.120 & 0.312 & 0.258 \\
\hline & $\mathrm{He}$ & 0.005 & 0.004 & 0.003 & 0.004 & 0.005 & 0.004 \\
\hline \multirow{3}{*}{$\begin{array}{l}\text { Cable } \\
\text { line }\end{array}$} & $E x$ & 0.171 & 0.049 & 0.540 & 0.480 & 0.488 & 0.707 \\
\hline & En & 0.128 & 0.076 & 0.406 & 0.391 & 0.312 & 0.258 \\
\hline & $\mathrm{He}$ & 0.003 & 0.003 & 0.002 & 0.003 & 0.005 & 0.004 \\
\hline \multirow{3}{*}{$\begin{array}{l}\text { Secon } \\
\text { dary } \\
\text { substa } \\
\text { tion }\end{array}$} & $E x$ & 0.132 & 0.026 & 0.468 & 0.580 & 0.488 & 0.707 \\
\hline & $E n$ & 0.015 & 0.029 & 0.037 & 0.045 & 0.312 & 0.258 \\
\hline & $\mathrm{He}$ & 0.002 & 0.003 & 0.004 & 0.003 & 0.005 & 0.004 \\
\hline
\end{tabular}

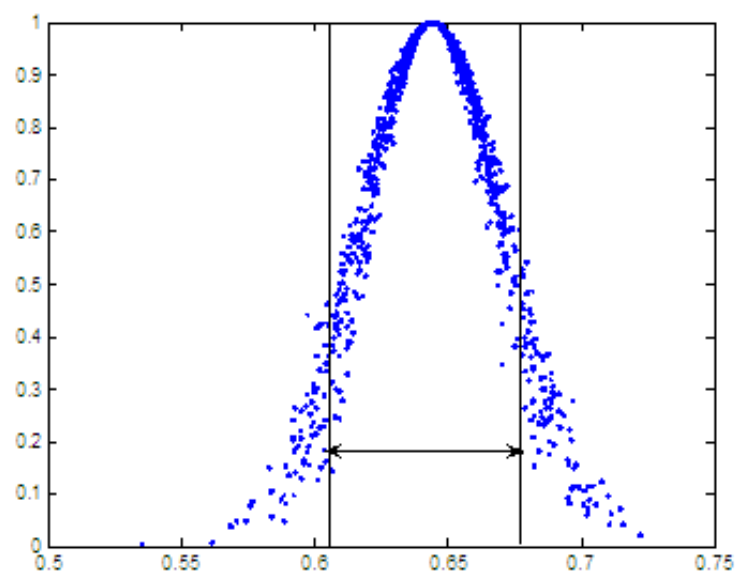

Figure 1. Over headline cloud

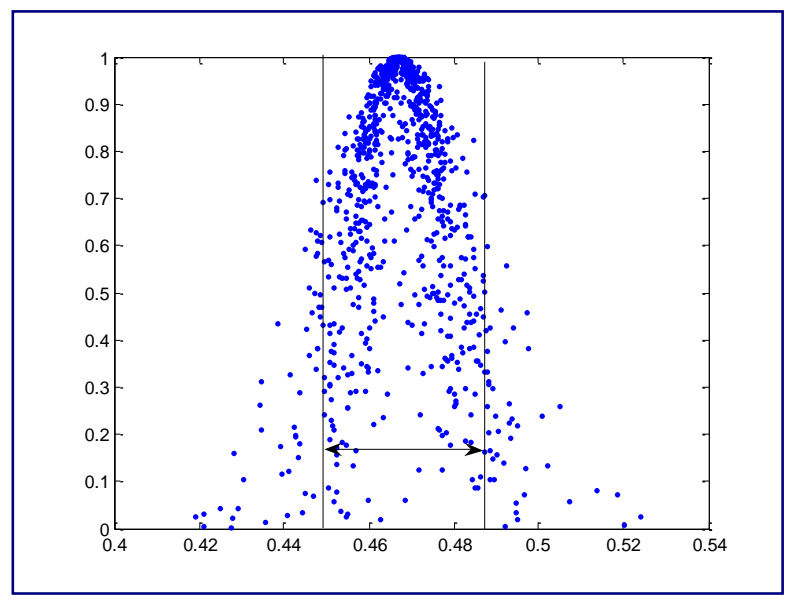

Figure 2. Pole transformer cloud

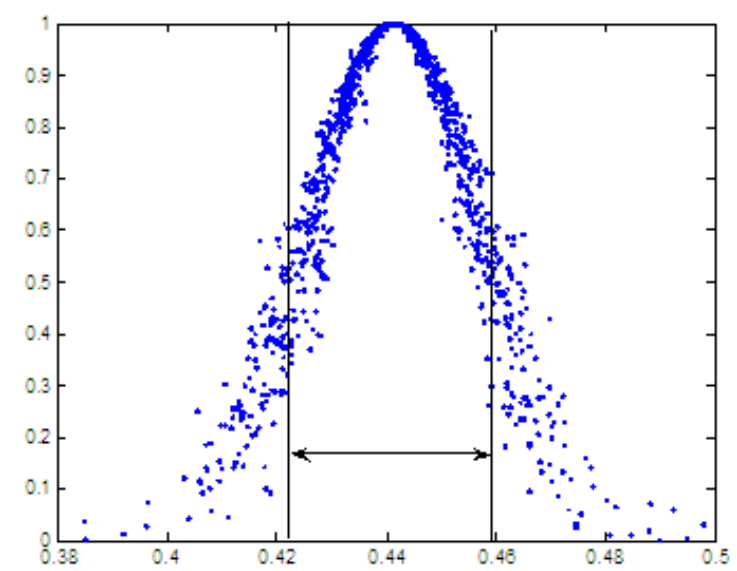

Figure 3. Pole equipment cloud

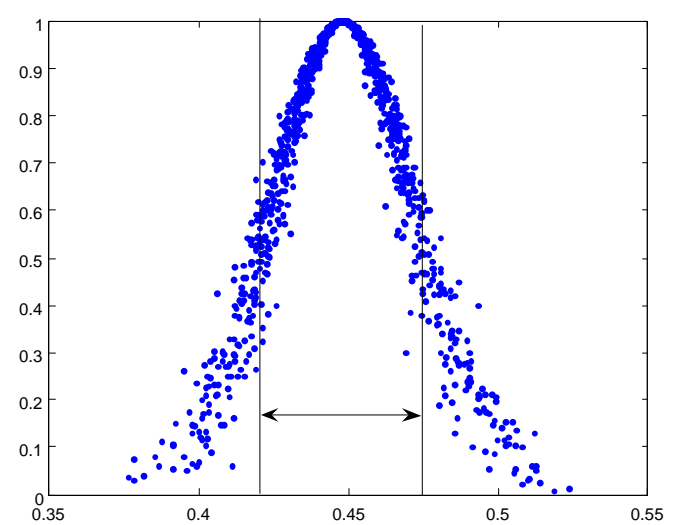

Figure 4. Cable line cloud

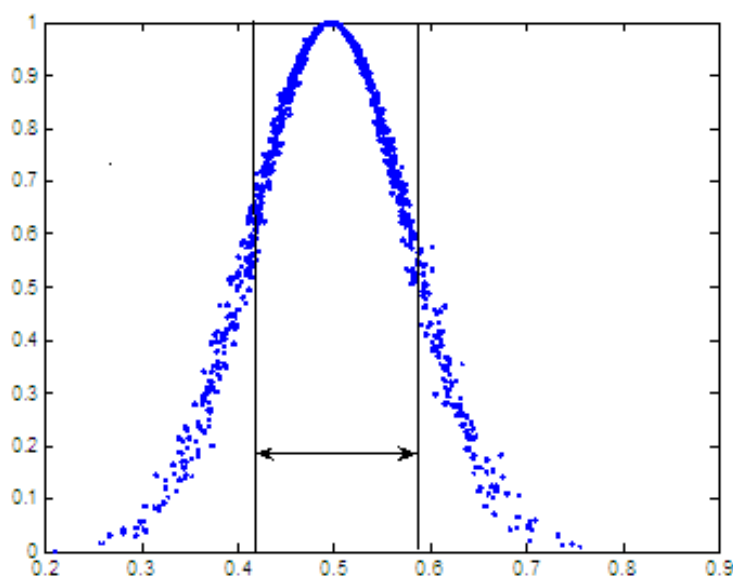

Figure 5. Secondary substation cloud

From Fig. 1 it can be seen that the cloud model of overhead lines produced by cloud droplets mainly falls on the risk interval $[0.55,0.7]$, accord with normal distribution, and the expected value for $E x=0.644$, the risk level of overhead line fault outage for 'high'. According to the calculated results of Table IV, forward cloud generator is 
used to generate cloud figure as Fig. 1 to 5. The index value of pole transformers, pole equipment, cable line, and secondary substation equipment level. According to the calculated results, overhead lines power failure was significantly higher than that of other power equipment, power utility is required to pay more attention to the prevention of overhead line fault risk, and reduce the probability of failure.

\section{CONCLUSIONS}

Based on the distribution network FI source analysis, this paper puts forward the key FI source and establishes the risk evaluation indicators for the distribution network. The risk evaluation method based on normal cloud model is proposed and was verified by a coastal city in south China distribution network. The test results show that the overhead lines index is the biggest number, and the power supply company should pay more attention on the inspection and maintenance of the overhead lines.

\section{REFERENCES}

[1] HU Xiaozheng,WANG Peng.Current Situation Analysis of Power Supply Reliability to Nationwide Urban Users in 2009[J].Distribution \& Utilization,2010,27(5):15-18,30.

[2] OFGEM. 2008/09 Electricity Distribution Quality of Service Report [R/OL]. http://www.ofgem.gov.uk/Networks/ ElecDist/ QualofServ/QoSIncent/Documents 1/200809\%20Electricity\%20 Distribution\%20Quality\%20of\%20Service\%20report.doc.pdf.
[3] OFGEM. 2008/09 Electricity Distribution Quality of Service Data Tables [R/OL]. http://www.ofgem.gov.uk/Networks/ElecDist/ QualofServ/QoSIncent/Documents 1/200809\%20QOS\%20data\%20 tables.xls

[4] WU Wen-chuan,NING Liao-yi,ZHUANG Bo-ming,SUN Hongbin.Online operational risk assessment and decision making for power systems[J].Journal of Changsha University of Electric Power(Natural Science Edition),2009(2).

[5] WU Wen-chuan,NING Liao-yi,ZHUANG Bo-ming,SUN Hongbin.Online operational risk assessment and decision making for power systems[J].JOurnal of Electric Power Science And Technology,2009,24(2):28-34

[6] Ni Ming,Mc Calley James D,Vittal V,eta.On-line risk-based security assessment [J].IEEE Transactions on Power Systems, 2003,18(1):258 -265 .

[7] Feng Yong qing,Wu Wenchuan, Zhang Boming, eta.Power system operation risk assessment using credibility theory [J].IEEE Transactions on Power Systems,2008,23(3):1309-1318

[8] China, DL 755-2001,Guide on security and stability for power system,2001.

[9] China, DL 836-2012, Reliability evaluation code for customer service in power supply system, 2012

[10] Li Deyi.Uncertainty in Knowledge Representation[J].Engineering Science, 2000,2(10):73-79.

[11] Li Deyi, Meng Haijun, Shi Xuemei.MEMBERSHIP CLOUDS AND MEMBERSHIP CLOUD GENERATORS[J].Journal of Computer Research and Development,1995,32(6):15-20.

[12] LI De Yi,LIU Chang Yu,DU Yi and HAN Xu. Artificial Intelligence with Uncertainty[J].Journal of Software, 2004, 15(11) 1583-1594. 